\title{
Unraveling the complexities of circadian and sleep interactions with memory formation through invertebrate research
}

\author{
Maximilian Michel ${ }^{1}$ and Lisa C. Lyons ${ }^{2 *}$ \\ ' Department of Molecular Physiology and Biophysics, Vanderbilt University School of Medicine, Nashville, TN, USA \\ ${ }^{2}$ Department of Biological Science, Program in Neuroscience, Florida State University, Tallahassee, FL, USA
}

\section{Edited by:}

Jason Robert Gerstner, Washington

State University, USA

\section{Reviewed by:}

György Kemenes, University of Sussex, UK

Kristin Eckel-Mahan, University of

California at Irvine, USA

*Correspondence:

Lisa C. Lyons, Department of Biological Science, Program in Neuroscience, Florida State University, 319 Stadium Drive, Tallahassee, FL 32306, USA e-mail: lyons@neuro.fsu.edu
Across phylogeny, the endogenous biological clock has been recognized as providing adaptive advantages to organisms through coordination of physiological and behavioral processes. Recent research has emphasized the role of circadian modulation of memory in generating peaks and troughs in cognitive performance. The circadian clock along with homeostatic processes also regulates sleep, which itself impacts the formation and consolidation of memory. Thus, the circadian clock, sleep and memory form a triad with ongoing dynamic interactions. With technological advances and the development of a global 24/7 society, understanding the mechanisms underlying these connections becomes pivotal for development of therapeutic treatments for memory disorders and to address issues in cognitive performance arising from non-traditional work schedules. Invertebrate models, such as Drosophila melanogaster and the mollusks Aplysia and Lymnaea, have proven invaluable tools for identification of highly conserved molecular processes in memory. Recent research from invertebrate systems has outlined the influence of sleep and the circadian clock upon synaptic plasticity. In this review, we discuss the effects of the circadian clock and sleep on memory formation in invertebrates drawing attention to the potential of in vivo and in vitro approaches that harness the power of simple invertebrate systems to correlate individual cellular processes with complex behaviors. In conclusion, this review highlights how studies in invertebrates with relatively simple nervous systems can provide mechanistic insights into corresponding behaviors in higher organisms and can be used to outline possible therapeutic options to guide further targeted inquiry.

Keywords: circadian rhythms, learning and memory, sleep, Aplysia, invertebrates

\section{SCOPE OF PROBLEM}

In the past century, the nature of human society has been dramatically altered by technological innovations, communication advances, transportation improvements and urbanization. Nontraditional work schedules and round-the-clock manufacturing shifts have become increasingly common worldwide with the proportion of individuals working non-traditional work schedules rising. Recent research indicates approximately 3.7\% of employed adult workers in the United States work a night shift with an additional $23.5 \%$ of individuals working non-traditional shifts including evening, rotating or split shifts (Luckhaupt, 2012; Alterman et al., 2013). Irregular work hours or jet lag desynchronize internal circadian oscillators that function to coordinate metabolic, physiological and behavioral processes in anticipation of daily environmental changes and orchestrate the timing of physiological and metabolic processes with behavioral activities.

Although the core circadian oscillator functions independently within individual cells, synchronization between oscillatory neurons and pacemakers is necessary to form functional circadian clocks for tissue and systems level rhythmicity (Albrecht, 2012). Neurons within the suprachiasmatic nucleus (SCN) are traditionally considered to comprise the master circadian clock in mammals. However, glial cells also have functional circadian oscillators and may modulate neuronal regulation of output rhythms (Prolo et al., 2005); for a review see Jackson (2011). Outside of the SCN, independent central circadian oscillators function within the olfactory bulb (Granados-Fuentes et al., 2004a,b, 2006) and rhythmic gene expression can be observed in multiple brain regions including the hippocampus (Holmes et al., 1995; Schaaf et al., 2000; Li et al., 2013). In mammals, as well as in lower vertebrates such as zebrafish (Whitmore et al., 2000) or invertebrates like Drosophila (Plautz et al., 1997), self-sustaining peripheral circadian oscillators can be found across multiple cell types and tissues including liver, heart, kidney, adrenal gland, pancreas and even fibroblasts (Balsalobre et al., 2000; Yoo et al., 2004), for reviews see Albrecht (2012) and Brown and Azzi (2013). These peripheral oscillators may be entrained at variable rates 
or through mechanisms in addition to SCN signaling such as the time of food intake, body temperature, or metabolite and hormonal signaling (reviewed in Dibner et al., 2010; Albrecht, 2012; Mohawk et al., 2012), confounding the necessary resynchronization of oscillators between multiple tissues following jet-lag, irregular work hours or behaviors.

Technological advances have created the phenomenon of social jet lag for many age groups in which individuals significantly shift their wake/sleep cycles on weekends compared to the work week resulting in a bi-weekly activity dependent phase-shifting of the circadian clock (Wittmann et al., 2006; Roenneberg, 2013). Adolescents, with their circadian rhythms developmentally shifted toward late night chronotypes in particular are susceptible to social jet lag, which can result in negative health consequences and cognitive decrements (Collado Mateo et al., 2012; Touitou, 2013; Haraszti et al., 2014). The rising trends in the number of individuals affected by shift work, technological advances and social jet lag have resulted in an increasing proportion of the population that can be considered to have circadian dysfunction.

At the level of the individual, career and societal pressures often result in longer work days with extended temporal demands for high performance leaving less time for rest (Knutson et al., 2010; Roenneberg, 2013). Based on self-reported data collected through national surveys in 2005 and 2010, onethird of adult U.S. workers (approximately 40.6 million individuals) sleep $6 \mathrm{~h}$ or less at night (Cdc, C.F.D.C.a.P., 2005, 2007-2010). Although some differing conclusions exist between studies, in general it appears that individuals in the 21 st century get significantly less rest compared to individuals 50-80 years ago, with rest time continuing to decrease over the last decade (Knutson et al., 2010; Bin et al., 2012; Luckhaupt, 2012; Roenneberg, 2013). Thus, the problems of sleep restriction, sleep disorders and circadian dysfunction appear pervasive in modern society.

Disturbances of the circadian clock through desynchronization or circadian dysfunction result in increased health problems for individuals with increased risk and incidence of metabolic diseases such as obesity and diabetes, cancer and heart disease as well as many other conditions (Barnard and Nolan, 2008; Preuss et al., 2008; Arble et al., 2010; Bass and Takahashi, 2010; Karatsoreos et al., 2011; Evans and Davidson, 2013; OrozcoSolis and Sassone-Corsi, 2014; Pluquet et al., 2014). Restricted sleep and sleep disorders also adversely impact individual health through increased risk of cardiovascular disease, immune system disorders, emotional and mood disorders, increased susceptibility to metabolic disorders, decreased cognitive performance and reduced quality of life and well-being (Breslau et al., 1996; Suka et al., 2003; Burgos et al., 2006; Neckelmann et al., 2007; Benca and Peterson, 2008; Goel et al., 2009; Vgontzas et al., 2009; Leproult and Van Cauter, 2010; Hsieh et al., 2011; Grandner et al., 2012). The increased incidence of automobile accidents, industrial accidents and occupational errors associated with sleep deprivation and sleep disorders raises the issue from the level of the individual to a societal crisis (Horne and Reyner, 1995; Pack et al., 1995; Lyznicki et al., 1998; Landrigan et al., 2004; Barger et al., 2005). Furthermore, decreased worker productivity leads to economic costs for businesses and industries with increased health problems exacerbating the loss in productivity by increasing health care costs to both employees and employers.

Independently of sleep deprivation or circadian dysfunction, the circadian clock itself modulates memory in humans and results in optimal times for memory and performance as well as trough phases in which significantly decreased performance in cognitive tasks occurs (Wright et al., 2002, 2006, 2012; Goel et al., 2013). This compounds the problems associated with shift work as circadian misalignment exists between the optimal times for cognitive performance and the phase in which some work is being performed. Moreover, when the effects of circadian phase such as work during a rest phase are compounded with extended time awake, the negative impacts on human cognitive performance are magnified (Dijk et al., 1992; Silva et al., 2010; Matthews et al., 2012b). Thus, the sleep restriction and fatigue faced by night shift workers, individuals in the transportation industry or health professionals, increase the problems associated with trying to optimize performance during sub-optimal circadian phases for cognitive performance. Additionally, the circadian clock can also modulate the impact of sleep deprivation on cognitive performance, further exacerbating the problem (Lo et al., 2012; Matthews et al., 2012a).

Despite the tremendous impact of sleep disorders and circadian dysfunction on individual health and society, the mechanisms and tri-partite interactions between sleep, the circadian clock and memory remain ill-defined at the synaptic or neuronal level. There is a continuing need for basic research investigating the underlying neural and molecular architecture involved in sleep, memory and circadian interactions in order to develop future treatments for disorders, improve cognitive performance, or design strategies to cope with the problems of shift work and social jet lag. Invertebrate research has proven to be fundamental in illuminating the basic principles and mechanisms underlying sleep, circadian rhythms and neuronal plasticity individually. In this review we will highlight recent advances that provide the framework and first steps to elucidate the interplay of these three research areas and discuss potential future directions.

\section{INVERTEBRATES IN NEUROBIOLOGY RESEARCH}

Given the considerable neuroanatomical differences between invertebrate models for neuroscience research (arthropods and mollusks) and higher organisms, differences in the levels of behavioral complexity, and the recent technological advances for targeted genetic studies in mammals, the reader may wonder whether research using invertebrate model systems will continue to advance progress in neuroscience research. Although vertebrate and invertebrate lineages diverged more than 900 million years ago (Peterson et al., 2004), the molecular and cellular mechanisms underlying neuronal behavior and synaptic plasticity are surprisingly well conserved across phylogeny. Understanding complex behaviors and the underlying cellular and molecular mechanism in higher organisms can be significantly facilitated through the study of these processes in comparatively less complex organisms.

Model systems such as Drosophila melanogaster and Caenorhabditis elegans have harnessed the power of neurogenetics 
to dissect mechanisms underlying behavior. For example, research in Drosophila was key in identifying mechanisms underlying the core circadian oscillator (reviewed in Allada and Chung, 2010; Hardin, 2011; Ozkaya and Rosato, 2012) as well as the identification of signaling pathways underlying associative memory formation (McGuire et al., 2005; Davis, 2011) to name just two examples. C. elegans has furthermore emerged as a genetic model for studying memory and aging (reviewed in Murakami, 2007; Stein and Murphy, 2012; Chen et al., 2013; Sasakura and Mori, 2013). The tractability of these invertebrate model systems has been enhanced by powerful neurogenetic techniques that include forward genetic screens, reverse genetic techniques with genome-wide RNAi lines available, and optogenetics to assess individual neuronal changes using voltage or calcium sensors (reviewed in Sattelle and Buckingham, 2006). Recent research in alcohol neurobiology and drug addiction using Drosophila has demonstrated how insights gained from invertebrates can be leveraged into rapid advances in mammalian systems (Corl et al., 2009; Kaun et al., 2012; Kapfhamer et al., 2013). Likewise, in sleep studies, research using invertebrate models has advanced research in higher organisms as was elegantly shown by Paul Shaw and colleagues. In these studies, candidate genes for putative biomarkers of sleep loss were identified in human and rodent models and tested in Drosophila, subsequently facilitating further studies of additional biomarkers in mammals (Thimgan et al., 2013). The tools available for invertebrate research provide cost-effective, experimentally tractable systems for the rapid identification of novel pathways and cellular interactions associated with defined behaviors that can subsequently be investigated in more complex model systems.

The large size, determinate neuron position and the relatively small number of neurons in Molluscan species such as the marine mollusk Aplysia californica have proven invaluable for characterizing changes in cellular signaling pathways and synaptic plasticity associated with memory formation (Kandel, 2001; Bailey et al., 2008; Kandel et al., 2014). Likewise, studies in the freshwater pond snail Lymnaea stagnalis have led to important insights into the mechanisms of memory formation, particularly for the modulation of memory (Kemenes et al., 2006; Marra et al., 2013; Lukowiak et al., 2014). Moreover, these invertebrates have been pivotal in the initial recognition of non-synaptic forms of neuronal plasticity and their possible role in the neuronal representation of memory (Mozzachiodi and Byrne, 2010; Nikitin et al., 2013). Lastly, studies of neuronal injury and plasticity using molluscan models have expanded our understanding of chronic pain and other neurological disorders in humans (reviewed in Weragoda and Walters, 2007; Walters and Moroz, 2009; Crook et al., 2013).

Thus, research in invertebrates provides the ability to study system level interactions with broad impacts throughout the organism on physiological, behavioral and metabolic processes, such as the circadian clock, sleep, drug and alcohol use and neurological diseases. Although differing biological and evolutionary constraints may give rise to vital differences between invertebrate and vertebrate systems, an understanding of how evolution solved essential and complex conserved phenomena such as the interplay between memory and sleep in "simple" organisms will provide crucial insight into the molecular and cellular building blocks underlying these phenotypes in man.

\section{SLEEP IN INVERTEBRATES}

To unravel the interactions between the circadian clock, sleep and memory formation, it is necessary to have a model system in which all three processes interact. The repeated appearance of sleep across phylogenies suggests that sleep is an evolutionary necessity and its functions are conserved, if not its origins. In mammals and birds, sleep consists of two main stages, slow wave sleep and rapid eye movement sleep (REM), characterized by changes in neuronal activity as measured by electroencephalograms (reviewed in Rattenborg, 2006; Madan and Jha, 2012). Despite the similarities in the two stage sleep state of these groups, the emergence of REM and NREM sleep appears to be through convergent evolution (Rattenborg, 2007; Rattenborg et al., 2012). In aquatic mammals, reptiles, amphibians and other vertebrates, slow wave sleep has been consistently detected although REM sleep is not always present (Hobson et al., 1968; Mukhametov et al., 1977; González et al., 1999) reviewed in Williams et al. (1973) and Madan and Jha (2012). Monotremes, such as the echidna and platypus, demonstrate a single sleep state that shows characteristics of both slow wave and REM sleep (Siegel et al., 1996, 1998, 1999; Nicol et al., 2000). The uni-hemispheric presentation of sleep such as observed in dolphins (Mukhametov et al., 1977; Mukhametov, 1987; Sekiguchi and Kohshima, 2003) or the appearance of local sleep in sub-regions of the brain may explain the absence or minimization of REM sleep in aquatic mammals and other non-mammalian vertebrates (reviewed in Madan and Jha, 2012; Rattenborg et al., 2012). Local sleep with concurrent changes limited to specific neuronal groups complicates the investigation of the mechanisms underlying the interactions of sleep, the circadian clock and synaptic plasticity or memory formation in higher organisms. As a first step, it is necessary to study all components within the same circuit or neuronal network making the lower complexity of invertebrates attractive for research. However, this raises the question "do invertebrates sleep in an analogous manner to higher organisms?"

Invertebrate sleep is defined by means of behavioral characteristics including rhythmic activity and rest behaviors, characteristic rest body posture, preferred resting location, decreased responsiveness to sensory stimuli during rest (increased arousal thresholds) and rebound following rest deprivation (homeostasis) (Tobler, 1983; Hendricks et al., 2000; Zimmerman et al., 2008). As the regulation of sleep occurs dually through homeostatic processes and the circadian clock (Borbély and Achermann, 1999), interaction of the rest state with the circadian clock or expression of clock genes may also be used to further define sleep. Using some or all of these criteria, sleep or sleep-like states have been identified in dozens of invertebrates across phyla. Table 1 highlights the activity phase and the type of sleep regulation observed for select invertebrate models that have also been used as models for studies of learning and memory or circadian research.

Recent advances using these relatively simple invertebrate systems have identified molecular and circuit mechanisms underlying sleep. For example, a sleep-like state has been reported for larval and adult stages of the nematode C. elegans in which 
Table 1 | Examples of invertebrate species from the Phyla Mollusca and Arthropoda in which sleep has been studied.

\begin{tabular}{|c|c|c|c|c|}
\hline & Organism & Activity Phase & Sleep characteristic & Reference \\
\hline \multirow[t]{4}{*}{$\begin{array}{l}\text { Phylum } \\
\text { Mollusca }\end{array}$} & Aplysia & Diurnal & $\begin{array}{l}\text { Homeostatic and Circadian } \\
\text { Regulation }\end{array}$ & $\begin{array}{l}\text { (Strumwasser, 1973; Vorster et al., } \\
\text { in press) }\end{array}$ \\
\hline & $\begin{array}{l}\text { Lymnaea stagnalis } \\
\text { (freshwater pond snail) }\end{array}$ & $\begin{array}{l}\text { Greater Activity During Early } \\
\text { Day }\end{array}$ & $\begin{array}{l}\text { Sporadic Bouts, Regulation } \\
\text { Unknown }\end{array}$ & $\begin{array}{l}\text { (Wagatsuma et al., 2004; Aono } \\
\text { et al., 2008; Stephenson and } \\
\text { Lewis, 2011) }\end{array}$ \\
\hline & Octopus & $\begin{array}{l}\text { Nocturnal with pronounced } \\
\text { dawn/dusk activity; may } \\
\text { vary }\end{array}$ & $\begin{array}{l}\text { Homeostatic and Circadian } \\
\text { Regulation }\end{array}$ & $\begin{array}{l}\text { (Brown et al., 2006; Meisel et al., } \\
\text { 2006; Hochner, 2010) }\end{array}$ \\
\hline & Sepia (Cuttlefish) & Diurnal, may vary & $\begin{array}{l}\text { Homeostatic Regulation, } \\
\text { Multiple Sleep-like States }\end{array}$ & $\begin{array}{l}\text { (Duntley et al., 2002; Hanlon et al., } \\
\text { 2007; Frank et al., 2012) }\end{array}$ \\
\hline \multirow[t]{4}{*}{$\begin{array}{l}\text { Phylum } \\
\text { Arthropoda }\end{array}$} & $\begin{array}{l}\text { Drosophila melanogaster } \\
\text { (fruitfly) }\end{array}$ & Diurnal; Crepuscular & $\begin{array}{l}\text { More sleep at night; } \\
\text { Homeostatic and Circadian } \\
\text { Regulation }\end{array}$ & $\begin{array}{l}\text { (Hendricks et al., 2000; Shaw } \\
\text { et al., 2000; van Alphen et al., } \\
\text { 2013) reviewed in Bushey and } \\
\text { Cirelli (2011) and Potdar and } \\
\text { Sheeba (2013) }\end{array}$ \\
\hline & Apis mellifera (honeybee) & Diurnal & $\begin{array}{l}\text { Varies with worker caste } \\
\text { and age; Multiple sleep } \\
\text { stages; Homeostatic and } \\
\text { Circadian Regulation }\end{array}$ & $\begin{array}{l}\text { (Kaiser and Steiner-Kaiser, 1983; } \\
\text { Kaiser, 1988; Sauer et al., 2003, } \\
\text { 2004; Eban-Rothschild and Bloch, } \\
\text { 2008, 2012; Klein et al., 2008) }\end{array}$ \\
\hline & $\begin{array}{l}\text { Leucophaea maderae; } \\
\text { Blaberus giganteus } \\
\text { (cockroach) }\end{array}$ & Nocturnal & $\begin{array}{l}\text { Homeostatic and Circadian } \\
\text { Regulation }\end{array}$ & $\begin{array}{l}\text { (Tobler, 1983; Tobler and } \\
\text { Neuner-Jehle, 1992; Decker et al., } \\
\text { 2007; Garren et al., 2013) }\end{array}$ \\
\hline & Procambrus clarkii (crayfish) & Diurnal & $\begin{array}{l}\text { Slow wave brain activity } \\
\text { during sleep, Homeostatic } \\
\text { regulation }\end{array}$ & $\begin{array}{l}\text { (Ramón et al., 2004; } \\
\text { Mendoza-Angeles et al., 2010; } \\
\text { Ramon et al., 2012) }\end{array}$ \\
\hline
\end{tabular}

quiescence is characterized by reduced sensory responsiveness, a characteristic rest body posture, and is timed through the expression of an ortholog of the canonical clock gene period (Jeon et al., 1999; You et al., 2008; Zimmerman et al., 2008; Iwanir et al., 2013; Nelson and Raizen, 2013). The simple wiring of the C. elegans nervous system allowed the identification of neuronal changes in sensory neurons and interneurons underlying the decreased arousal and quick reversibility of quiescence (Schwarz et al., 2011; Cho and Sternberg, 2014). At the molecular level, regulation of this sleep-like behavior has been associated with changes in the expression of highly conserved transcription factors (Driver et al., 2013; Turek et al., 2013) and neuropeptide signaling (Nelson and Raizen, 2013). The rapidity of research advances in the identification of the molecular and cellular mechanisms underlying sleep in C. elegans highlights the usefulness and potential for simple invertebrates in sleep research.

In insects, detailed studies of sleep have been performed in many species including cockroaches, bees, mosquitoes and Drosophila (Tobler, 1983; Tobler and Neuner-Jehle, 1992; Hendricks et al., 2000; Shaw et al., 2000; Eban-Rothschild and Bloch, 2008; Klein et al., 2008; Bushey et al., 2011). Over the past 15 years, our understanding of the functions of sleep and its functional necessity has rapidly progressed through research in Drosophila (reviewed in Cirelli and Tononi, 2008; Piscopo, 2009; Potdar and Sheeba, 2013) by providing evidence for the synaptic homeostasis hypothesis of sleep proposed by Tononi and Cirelli (2003). The synaptic homeostasis hypothesis is similar to synaptic scaling or homeostatic plasticity proposed for learning and memory (for a recent review see Schacher and $\mathrm{Hu}, 2014$ ) and suggests that periods of activity with concomitant increases in synaptic strength are followed by synaptic downscaling during periods of sleep including decreases in synapse number (synaptic pruning) and weakening of synaptic connections (reviewed in Tononi and Cirelli, 2006, 2012). Structural evidence for synaptic pruning during sleep was recently provided in Drosophila (Bushey et al., 2011) along with the identification of sleep/wake changes in synaptic markers (Gilestro et al., 2009) consistent with the synaptic homeostasis hypothesis. Drosophila as a model has also been invaluable in advancing our understanding of the role of experience dependent plasticity in the need for sleep (Donlea et al., 2009) and the role of sleep in memory consolidation (Donlea et al., 2011). Furthermore, sleep in Drosophila also occurs in different stages with a deeper intensity sleep stage evident through recordings of brain activity (van Alphen et al., 2013). The rapid generation time of Drosophila combined with powerful neurogenetic approaches and forward genetic screens have allowed researchers to identify numerous genes and pathways regulating arousal and sleep (Koh et al., 2008; Chen et al., 2014; Park et al., 2014; Shi et al., 2014; Wu et al., 2014) as well as the timing of sleep onset (Liu et al., 2014). These factors have propelled Drosophila to the forefront of sleep research as a future model for screening and thereby understanding the genetic basis for sleep disorders in humans (Freeman et al., 2013). Despite these incredible and rapid advances in sleep research and the relatively small size of the Drosophila brain compared to mammalian brains, the complexity of the Drosophila nervous system combined with small neuronal size still poses some difficulties in decoding the tripartite interactions of sleep, the 
circadian clock and memory formation within the same neuronal circuit.

In the morphologically diverse phylum Mollusca, conservation of sleep has been shown with sleep-like states characterized in Cephalopods and Gastropods. Cephalopods are often referred to as advanced invertebrates (Zullo and Hochner, 2011), as they have a highly developed centralized nervous systems and complex behaviors including higher order learning. Octopus vulgaris and the cuttlefish Sepia demonstrate sleep similar to vertebrate organisms with corresponding changes in behavior and differential brain activity (Duntley et al., 2002; Brown et al., 2006; Frank et al., 2012). However, increasing difficulties of working with cephalopods in laboratory settings and concerns for animal welfare (Fiorito et al., 2014) combined with the complexity of the cephalopod central nervous system make further studies of circadian and sleep interaction with memory or synaptic plasticity more difficult.

In comparison to cephalopods, gastropods are very different in morphological organization and development of the nervous system with a relatively simple central nervous systems and neurons clustered in distributed ganglia. Gastropods, including the terrestrial snail Helix, the pond snail Lymnaea, and the sea slugs Hermissenda and Aplysia have long been favorite models for neuroscience research and studies of synaptic plasticity. Anecdotal evidence and isolated literature references in early circadian and behavioral studies suggested resting or quiescent sleep states in Aplysia (Strumwasser, 1971, 1973; Preston and Lee, 1973), although systematic analysis of Aplysia sleep has only occurred recently. Aplysia sleep appears monophasic along circadian time with rest occurring only during the night. Aplysia further exhibit decreased sensory responsiveness during rest and sleep rebound following manual rest deprivation (Vorster et al., in press). Although the nervous system of the related gastropod Lymnaea stagnalis appears similar to Aplysia, surprisingly, rest-like states appear to be very different, with rest occurring infrequently and sporadically totaling less than $10 \%$ of the time (Stephenson and Lewis, 2011). Moreover, Lymnaea sleep does not appear to be regulated by the circadian clock, and rebound rest following deprivation has not been shown (Stephenson and Lewis, 2011; Stephenson, 2011). From these studies one could conclude either that Lymnaea require little sleep based upon their ecological niche or that sleep may be regulated via other mechanisms. Alternately, one may hypothesize that behavioral measures of sleep may not always be sufficient to characterize sleep and further investigations in simple invertebrates should be conducted to determine if sleep occurs at the level of the individual neuron. Although detailed characterization of the role of sleep in memory formation and synaptic plasticity has not yet been done in Lymnaea or Aplysia, the demonstration of sleep in these organisms highlights the potential for future research investigating the function and role of sleep in neuronal plasticity and memory formation using these classic neuroscience models.

\section{THE CIRCADIAN CLOCK AND MEMORY}

Energetically, neuronal and synaptic activities are expensive with the brain consuming about 20\% of the total energy budget (reviewed in Harris et al., 2012). Behavioral evidence for the higher costs of neuronal activity and synaptic plasticity can be found in Drosophila (reviewed in Burns et al., 2011). Long-term memory formation is limited when starvation conditions exist (Plaçais and Preat, 2013) and memory formation decreases the resistance of flies to extreme stress (Mery and Kawecki, 2005). An evolutionary tradeoff exists in Drosophila between longevity and memory formation with longer-lived strains showing lower levels of memory (Burger et al., 2008; Lagasse et al., 2012). Likewise, selection of strains of flies with increased long-term memory results in decreases in longevity presumably due to the high metabolic costs associated with the improvements in memory and performance (Burger et al., 2008; Lagasse et al., 2012). One of the underlying tenets of the synaptic homeostasis hypothesis for sleep is that stronger synapses and strengthening of synapses during waking lead to higher energy consumption, that can be compensated for with synaptic downscaling during sleep which permits decreases in energy consumption allowing energy balance and restoration of cellular homeostasis (reviewed in Tononi and Cirelli, 2014). Thus while sleep functions as one mechanism for restoring energy balance, the energy demands associated with memory formation still exert a strong selective pressure for limiting memory formation as can be seen with the longevity studies in Drosophila.

One possible mechanism to restrict memory formation in concert with the animal's activity and physiology is through circadian modulation of memory. The far-reaching impact of the circadian clock on physiology can be observed through the adverse impacts associated with circadian dysfunction or desynchronization. Circadian dysfunction increases the risk of disease incidence for heart disease, metabolic diseases such as diabetes, multiple forms of cancer, mood disorders (reviewed in Barnard and Nolan, 2008; Preuss et al., 2008; Arble et al., 2010; Bass and Takahashi, 2010; Karatsoreos et al., 2011; Evans and Davidson, 2013; Orozco-Solis and Sassone-Corsi, 2014; Pluquet et al., 2014) as well as decrements in cognitive performance (Cho et al., 2000; Gibson et al., 2010; Loh et al., 2010). The broad scope of circadian modulation of metabolism and physiology suggests that there may be multiple levels through which the circadian clock could impact memory formation including sensory gating, enzymatic activity, intracellular signaling cascades, macromolecular synthesis or epigenetic regulation.

Interestingly, the mechanisms through which the circadian clock impacts memory appears to depend upon the type of learning, e.g., non-associative, classical or operant, and the type of memory formed, e.g., short, intermediate or long-term memory. Furthermore, the circadian clock may target memory through its induction, molecular consolidation, and/or recall. Focusing on invertebrate research, circadian modulation of memory has been observed in both insects and mollusks (see Table 2 for examples). In cockroaches, short and long-term memories induced through classical olfactory conditioning are highly dependent upon time of training (Decker et al., 2007). Interestingly, during operant conditioning the circadian clock modulates recall, rather than memory formation, demonstrating how the circadian clock may regulate different steps in memory (Garren et al., 2013). In Drosophila, circadian modulation of olfactory conditioning has been shown directly for short-term 
Table 2 | Examples of species frequently used for learning and memory studies in which sleep or circadian modulation of memory has also been examined.

\begin{tabular}{|c|c|c|c|c|}
\hline & Organism & Learning Paradigm & Type of Modulation & Reference \\
\hline \multirow[t]{6}{*}{$\begin{array}{l}\text { Phylum } \\
\text { Mollusca }\end{array}$} & Aplysia & Sensitization & $\begin{array}{l}\text { Circadian modulation of } \\
\text { intermediate and long-term } \\
\text { memory formation, peak } \\
\text { memory during the day }\end{array}$ & $\begin{array}{l}\text { (Fernandez et al., 2003; Lyons } \\
\text { et al., 2006a,b, 2008) }\end{array}$ \\
\hline & & $\begin{array}{l}\text { Operant } \\
\text { conditioning-feeding } \\
\text { behavior }\end{array}$ & $\begin{array}{l}\text { Circadian modulation of } \\
\text { intermediate and long-term } \\
\text { memory formation, peak } \\
\text { memory during the day for } \\
\text { diurnal } A \text {. californica. Peak } \\
\text { long-term memory at night for } \\
\text { nocturnal species }\end{array}$ & $\begin{array}{l}\text { (Lyons et al., 2005, 2006b; } \\
\text { Michel et al., 2013) }\end{array}$ \\
\hline & & $\begin{array}{l}\text { Habituation, Classical } \\
\text { Conditioning }\end{array}$ & Not Examined & Reviewed in Kandel (2001) \\
\hline & $\begin{array}{l}\text { Lymnaea stagnalis } \\
\text { (pond snail) }\end{array}$ & Conditioned taste aversion & $\begin{array}{l}\text { Diurnal modulation; peak } \\
\text { learning in early morning }\end{array}$ & $\begin{array}{l}\text { (Wagatsuma et al., 2004; } \\
\text { Stephenson and Lewis, 2011) }\end{array}$ \\
\hline & Octopus & $\begin{array}{l}\text { Avoidance learning, Touch } \\
\text { Discrimination, long-term } \\
\text { potentiation }\end{array}$ & Not Examined & $\begin{array}{l}\text { (Wells, 1965; Wells and Young, } \\
\text { 1965; Hochner et al., 2003; } \\
\text { Shomrat et al., 2008; Hochner, } \\
\text { 2010) }\end{array}$ \\
\hline & Sepia (Cuttlefish) & $\begin{array}{l}\text { Spatial memory, } \\
\text { associative memory }\end{array}$ & Not Examined & $\begin{array}{l}\text { (Duntley et al., 2002; Alves et al., } \\
\text { 2007; Frank et al., 2012; Cartron } \\
\text { et al., 2013) }\end{array}$ \\
\hline
\end{tabular}

\begin{tabular}{lll}
\hline Phylum & Drosophila & Aversive phototactic \\
Arthropoda & melanogaster (fruitfly) & suppression \\
& & Courtship Conditioning
\end{tabular}

Sleep deprivation affects short and long-term memory Sleep deprivation impacts long-term memory; increased sleep enhances long-term memory

Olfactory memory Apis mellifera (honeybee)

$\begin{array}{ll} & \text { Spatial memory } \\ \begin{array}{l}\text { Leucophaea maderae } \\ \text { (cockroach) }\end{array} & \text { Olfactory memory } \\ \begin{array}{l}\text { Manduca sexta } \\ \text { (hawkmoth) } \\ \text { Chasmagnathus (crab) }\end{array} & \text { Olfactory memory } \\ \end{array}$

Circadian and diurnal modulation of short and long-term memory Sleep deprivation affects short-term memory and long-term memory

Decreased sleep impairs memory

Diurnal and circadian modulation of memory; Sleep deprivation affects extinction learning Sleep deprivation affects memory consolidation

Circadian regulation of short and long-term memory; stage of modulation varies between classical and operant paradigms Diurnal regulation of short and intermediate-term memory Non-24 h intervals between training and testing impair long-term memory
(Seugnet et al., 2009, 2011)

(Ganguly-Fitzgerald et al., 2006; Donlea et al., 2011)

(Lyons and Roman, 2008; Fropf et al., 2014)

(Li et al., 2009; Le Glou et al., 2012)

(Bushey et al., 2007)

(Hussaini et al., 2009; Lehmann et al., 2011)

(Moore and Doherty, 2009;

Moore et al., 2011; Beyaert et al. 2012)

(Tobler, 1983; Tobler and

Neuner-Jehle, 1992; Decker et al., 2007; Garren et al., 2013)

(Gage et al., 2013; Gage and

Nighorn, 2014)

(Pereyra et al., 1996) and long-term memory (Lyons and Roman, 2008; Fropf et al., 2014) as well indirectly via circadian modulation of the vulnerability of anesthesia resistant memory to sleep deprivation (Le Glou et al., 2012). A recent study furthermore starts to unravel the molecular mechanisms by implicating circadian changes of a constitutive transcription factor well known for its role in long-term memory (Fropf et al., 2014). Core circadian clock genes also affect long-term memory formation as shown for courtship conditioning (Sakai et al., 2004). In honeybees, learning and memory are also modulated by the circadian timing of training (Lehmann et al., 2011). These studies in insects clearly demonstrate that circadian regulation of memory can 
occur at multiple stages including the formation and recall of memory.

In addition to the circadian clock itself modulating memory or recall, core circadian genes also function in synaptic plasticity outside of their roles in the circadian oscillator. Independent of its canonical role in the Drosophila central pacemaker, the bluelight sensor CRYPTOCHROME (CRY) has the ability to mediate neuronal firing rates in response to light through potassium channel conductance (Fogle et al., 2011). Furthermore, the core clock protein PERIOD (PER) appears necessary for robust longterm memory as per mutant flies exhibit deficits in conditioned courtship memory (Sakai et al., 2004). Similar complexity in circadian regulation of memory at multiple levels has also been observed in vertebrates (reviewed in Gerstner and Yin, 2010; Jilg et al., 2010; Bechstein et al., 2014).

Circadian modulation of memory dependent upon the time of training has also been shown for intermediate and longterm memory in mollusks where the most extensive studies have been conducted in Aplysia (reviewed in Lyons, 2011). Using a non-associative form of learning, sensitization of the tail-siphon withdrawal reflex, it was found that both protein synthesis dependent intermediate-term memory and long-term memory were regulated by the circadian clock dependent upon time of training (Fernandez et al., 2003; Lyons et al., 2008). Although long-term memory in this case appears to be regulated only during its induction and formation, multiple processes are regulated by the circadian clock following training including neurotransmitter release, the induction of MAPK signaling and immediate early gene expression (Lyons et al., 2006a). The circadian clock also modulates intermediate and long-term memory for an associative operant learning paradigm (Lyons et al., 2005; Michel et al., 2013). In contrast to the circadian regulation of short-term memory observed in insects, Aplysia short-term memory for either associative or non-associative paradigms does not appear to be regulated by the circadian clock (Fernandez et al., 2003; Lyons et al., 2005), perhaps due to the specific ethological relevance of the learning paradigms used in these studies, a defensive reflex and feeding behavior. In Lymnaea, time of day also affects the acquisition of memory for conditioned taste aversion (Wagatsuma et al., 2004). The appearance of strong circadian modulation of memory across species and learning paradigms demonstrates that this modulation provides a clear evolutionary advantage. Recently, studies in rodents have shown that the reverse modulation also occurs, i.e., that memory formation can impact the circadian timekeeping of the organism. Using a hippocampal dependent learning paradigm and sustained activity tasks, researchers demonstrated that training inducing memory formation conducted during the animal's inactive period resulted in a phase shift in locomotor activity (Gritton et al., 2012). Although the potential bidirectional interaction of memory formation and synaptic activity on the phase of the circadian clock have not been investigated using invertebrate models, understanding the impact of memory formation anti-phase to activity cycles will be important for managing the issues of memory and performance associated with shift work. Thus, it will be of considerable interest to identify the molecular mechanisms of this interaction as well as the parameters and circumstances under which these bi-directional influences occur.
Invertebrate models provide excellent systems for investigating the forward modulation of memory by the circadian clock and identifying the types and mechanisms through which memory or cognitive activity impact the circadian oscillator or other circadian rhythms.

\section{FUTURE DIRECTIONS}

Identifying the individual neurons and neural networks causal to complex behaviors and studying the interactions between multiple processes such as memory, sleep and the clock is one of the greatest challenges in modern neuroscience. Using invertebrate model systems, it becomes feasible to investigate the interactions of sleep, the circadian clock and synaptic plasticity at the level of individual neurons or neuronal circuits permitting the possibility of addressing the following topics: (1) determine how individual neurons or neuronal circuits involved in memory formation are stabilized through time, reactivated, undergo periods of malleability and degradation/pruning; (2) determine how the effects of sleep as a network property or at the level of individual neurons affects neuronal plasticity; (3) determine how the core circadian clock regulates sleep in individual neurons and circuits; (4) determine how sleep and circadian time modulate neuronal and synaptic activity for specific tasks or memories; (5) determine how effects analogous to modern life such as non-traditional sleep/wake cycles or shifted circadian rhythms affect this interplay transiently and chronically; and ultimately; (6) identify mechanisms through which these interactions can be modified by drugs or optimized behavioral patterns.

In support of this, recent studies in invertebrates have identified specific neurons that regulate sleep (Donlea et al., 2014) as well as a circadian transcript that modulates sleep onset in Drosophila (Liu et al., 2014). Sleep has also been shown to regulate net synaptic homeostasis, thereby "resetting" the nervous system to allow future plasticity (Tononi and Cirelli, 2014). From this and the studies mentioned in the previous sections it follows that the molecular and cellular substrate for the interplay between memory, sleep and the clock is slowly crystallizing from invertebrate studies, and this will significantly inform follow up research in mammalian and simian species.

One of the greatest benefits of the molluscan model system is the spectrum of techniques permitting an integration of topdown (in-vivo) and bottom-up (in vitro) approaches in the experimental design and the exquisite detail possible with investigations at the level of individual neurons or neuronal circuits. In gastropod mollusks, the precisely wired nervous system is comprised of large neurons with determinate location and in many cases functions of individual neurons identified (see for example Benjamin et al., 2000; Moroz, 2000; Kandel, 2001; Kandel et al., 2014). In models such as Lymnaea and Aplysia, the advantages of multilevel approaches combining in vivo behavioral studies with in vitro cellular studies to correlate complex behaviors with individual neuronal behavior have been well-documented.

For example in Aplysia, long-term facilitation provides a cellular correlate for behavioral sensitization that can be investigated in reduced preparations and cultured neurons (see for example Kandel, 2001; Hawkins et al., 2006). In a semi-intact reduced preparation in which the siphon and tail are exposed with the 
nerves connecting the ganglia left intact, intermediate and longterm sensitization can be studied for either the tail-siphon withdrawal reflex or for a tail-tail withdrawal reflex (Philips et al., 2006, 2011). The existence of extra-ocular photoreceptors and extra-ocular circadian oscillators involved in circadian modulation of memory in Aplysia (Lyons et al., 2006b) widens the potential for studying system level interactions between the circadian clock and memory formation using semi-intact reduced or whole ganglia preparations. Furthermore, sleep has been characterized in Aplysia that demonstrates changes in sensory arousal accompanying sleep and homeostatic rebound rest following sleep deprivation (Vorster et al., in press). Individual neuronal changes correlated with behavioral changes can be identified using well-developed whole mount immunohistochemical and in situ techniques as shown in Aplysia (Sweedler et al., 2002; Jezzini et al., 2005). The neurons known to underlie behavioral effects seen in vivo as well as in the reduced preparation can further be co-cultured in a dish (Cai et al., 2012), or a compartmentalized dish to separately investigate synaptic vs. somatic changes within the neurons (Ye et al., 2012). Moreover, the large size of Aplysia neurons and determinate neuronal position also allows for genomic and metabolomic analysis at the scale of the individual neuron (Moroz and Kohn, 2013; Nemes et al., 2013), or even the synaptic transcriptome (Puthanveettil et al., 2013).

Similar anatomical advantages for studies of individual neurons or neuronal circuits exist in Lymnaea in which multielectrode arrays have been used in order to record from up to 60 electrodes simultaneously (Harris et al., 2010). Additionally, the large neuronal size permits investigation of plasticity at subcellular levels using behavioral, electrophysiological and optical recording techniques. For example, recent research in Lymnaea demonstrated that learning-induced non-synaptic plasticity contributed to specific, compartmentalized presynaptic changes through calcium signaling (Nikitin et al., 2013). The advantages of large neuronal size and the potential for individual neuronal manipulations through pharmacological or electrophysiological methods combined with the diversity of recording techniques ensures that molluscan neuronal circuits will remain at the forefront of our progress in studies of synaptic plasticity and neuronal behavior.

Given the availability of abundant data underlying neuronal network function in molluscs, mathematical modeling can be leveraged to drive further experimental inquiry (Vavoulis et al., 2007; Liu et al., 2013). Importantly, the incorporation of predictive neuronal networks to direct experimental investigations facilitates the identification of key signaling molecules in behavior and methods to ameliorate conditions caused by mutations in these pathways. In a set of elegant studies, the Byrne lab has modeled the molecular underpinnings of Aplysia memory processes to develop a training paradigm predicted to lead to a stronger induction of the molecular cascades necessary for memory. Testing these predictions behaviorally, they found that the modeled training protocols resulted in stronger and longer lasting memory (Zhang et al., 2011). In subsequent studies, the power of computer simulations was leveraged to predict an ameliorated training paradigm to overcome the knockdown of a protein commonly mutated in Rubinstein-Taybi syndrome, strongly suggesting that modeling using the molecular and circuit level insight gained from invertebrates can be used to predict optimal learning strategies potentially in lieu of or in conjunction with drug therapy (Liu et al., 2013).

The multi-level combinatorial approaches outlined above set the stage to yield unprecedented insight into the mechanisms through which sleep or the circadian clock affects neuronal plasticity. The high degree of phylogenetic conservation as previously discussed permits the rapid translation of research in invertebrate systems to mammalian models (see also Abrams, 2012). It stands to reason that even with evolutionary differences resulting in nonconserved transcripts between invertebrates and mammals, the role that these molecules play will have an analogous function in mammals since the circadian clock, sleep and memory are evolutionarily well-conserved processes. Taken together, research in relatively simple mollusks such as Aplysia presents the scientific community with a powerful toolset to identify the cellular and molecular pathways from the whole animal to mathematical models, laying the foundation to identify the basic principles and mechanisms of memory modulation. Unraveling the intricate relationships between sleep, the circadian clock and learning and memory is essential to identify key molecules or interacting nodes for the development of future therapies to improve cognitive performance and decrements associated with shift work, sleep disorders, aging or neurological disorders.

\section{ACKNOWLEDGMENTS}

Research support for Lisa C. Lyons provided by National Institute on Alcohol Abuse and Alcoholism grant R21AA021233, National Institute of Neurological Disorders and Stroke grant R21NS088835 and a grant from the Center for Research and Creativity at Florida State University. Maximilian Michel was supported by NIH Training Grant in Neurogenomics T32-MH65215.

\section{REFERENCES}

Abrams, T. W. (2012). Studies on Aplysia neurons suggest treatments for chronic human disorders. Curr. Biol. 22, R705-R711. doi: 10.1016/j.cub.2012. 08.011

Albrecht, U. (2012). Timing to perfection: the biology of central and peripheral circadian clocks. Neuron 74, 246-260. doi: 10.1016/j.neuron.2012.04.006

Allada, R., and Chung, B. Y. (2010). Circadian organization of behavior and physiology in Drosophila. Annu. Rev. Physiol. 72, 605-624. doi: 10.1146/annurevphysiol-021909-135815

Alterman, T., Luckhaupt, S. E., Dahlhamer, J. M., Ward, B. W., and Calvert, G. M. (2013). Prevalence rates of work organization characteristics among workers in the U.S.: data from the 2010 National Health Interview Survey. Am. J. Ind. Med. 56, 647-659. doi: 10.1002/ajim.22108

Alves, C., Chichery, R., Boal, J. G., and Dickel, L. (2007). Orientation in the cuttlefish Sepia officinalis: response versus place learning. Anim. Cogn. 10, 2936. doi: 10.1007/s10071-006-0027-6

Aono, K., Fusada, A., Fusada, Y., Ishii, W., Kanaya, Y., Komuro, M., et al. (2008). Speed of back-swimming of Lymnaea. Acta Biol. Hung. 59(Suppl.), 105-109. doi: 10.1556/abiol.59.2008.suppl.17

Arble, D. M., Ramsey, K. M., Bass, J., and Turek, F. W. (2010). Circadian disruption and metabolic disease: findings from animal models. Best Pract. Res. Clin. Endocrinol. Metab. 24, 785-800. doi: 10.1016/j.beem.2010.08.003

Bailey, C. H., Barco, A., Hawkins, R. D., Kandel, E. R., and John, H. B. (2008). "Molecular studies of learning and memory in Aplysia and the hippocampus: a comparative analysis of implicit and explicit memory storage," in Learning and Memory: A Comprehensive Reference, Vol. 4, eds David J. Sweatt and John 
H. Byrne (Oxford: Academic Press), 11-29. doi: 10.1016/B978-0123705099.00191-1

Balsalobre, A., Brown, S. A., Marcacci, L., Tronche, F., Kellendonk, C., Reichardt, H. M., et al. (2000). Resetting of circadian time in peripheral tissues by glucocorticoid signaling. Science 289, 2344-2347. doi: 10.1126/science.289.5488. 2344

Barger, L. K., Cade, B. E., Ayas, N. T., Cronin, J. W., Rosner, B., Speizer, F. E., et al. (2005). Extended work shifts and the risk of motor vehicle crashes among interns. N. Engl. J. Med. 352, 125-134. doi: 10.1056/NEJMoa041401

Barnard, A. R., and Nolan, P. M. (2008). When clocks go bad: neurobehavioural consequences of disrupted circadian timing. PLoS Genet. 4:e1000040. doi: 10. 1371/journal.pgen.1000040

Bass, J., and Takahashi, J. S. (2010). Circadian integration of metabolism and energetics. Science 330, 1349-1354. doi: 10.1126/science.1195027

Bechstein, P., Rehbach, N. J., Yuhasingham, G., Schürmann, C., Göpfert, M., Kössl, M., et al. (2014). The clock gene period1 regulates innate routine behaviour in mice. Proc. Biol. Sci. 281:20140034. doi: 10.1098/rspb.2014.0034

Benca, R. M., and Peterson, M. J. (2008). Insomnia and depression. Sleep Med. 9(Suppl. 1), S3-S9. doi: 10.1016/S1389-9457(08)70010-8

Benjamin, P. R., Staras, K., and Kemenes, G. (2000). A systems approach to the cellular analysis of associative learning in the pond snail Lymnaea. Learn. Mem. 7, 124-131. doi: 10.1101/lm.7.3.124

Beyaert, L., Greggers, U., and Menzel, R. (2012). Honeybees consolidate navigation memory during sleep. J. Exp. Biol. 215, 3981-3988. doi: 10.1242/jeb.075499

Bin, Y. S., Marshall, N. S., and Glozier, N. (2012). Secular trends in adult sleep duration: a systematic review. Sleep Med. Rev. 16, 223-230. doi: 10.1016/j.smrv. 2011.07.003

Borbély, A. A., and Achermann, P. (1999). Sleep homeostasis and models of sleep regulation. J. Biol. Rhythms 14, 557-568. doi: 10.1177/0748730991290 00894

Breslau, N., Roth, T., Rosenthal, L., and Andreski, P. (1996). Sleep disturbance and psychiatric disorders: a longitudinal epidemiological study of young adults. Biol. Psychiatry 39, 411-418. doi: 10.1016/0006-3223(95)00188-3

Brown, S. A., and Azzi, A. (2013). Peripheral circadian oscillators in mammals. Handb. Exp. Pharmacol. 217, 45-66. doi: 10.1007/978-3-642-25950-0_3

Brown, E. R., Piscopo, S., De Stefano, R., and Giuditta, A. (2006). Brain and behavioural evidence for rest-activity cycles in Octopus vulgaris. Behav. Brain Res. 172, 355-359. doi: 10.1016/j.bbr.2006.05.009

Burger, J. M., Kolss, M., Pont, J., and Kawecki, T. J. (2008). Learning ability and longevity: a symmetrical evolutionary trade-off in Drosophila. Evolution 62, 1294-1304. doi: 10.1111/j.1558-5646.2008.00376.x

Burgos, I., Richter, L., Klein, T., Fiebich, B., Feige, B., Lieb, K., et al. (2006). Increased nocturnal interleukin-6 excretion in patients with primary insomnia: a pilot study. Brain Behav. Immun. 20, 246-253. doi: 10.1016/j.bbi.2005. 06.007

Burns, J. G., Foucaud, J., and Mery, F. (2011). Costs of memory: lessons from 'mini' brains. Proc. Biol. Sci. 278, 923-929. doi: 10.1098/rspb.2010.2488

Bushey, D., and Cirelli, C. (2011). From genetics to structure to function: exploring sleep in Drosophila. Int. Rev. Neurobiol. 99, 213-244. doi: 10.1016/b978-0-12387003-2.00009-4

Bushey, D., Huber, R., Tononi, G., and Cirelli, C. (2007). Drosophila Hyperkinetic mutants have reduced sleep and impaired memory. J. Neurosci. 27, 5384-5393. doi: 10.1523/jneurosci.0108-07.2007

Bushey, D., Tononi, G., and Cirelli, C. (2011). Sleep and synaptic homeostasis: structural evidence in Drosophila. Science 332, 1576-1581. doi: 10.1126/science. 1202839

Cai, D., Pearce, K., Chen, S., and Glanzman, D. L. (2012). Reconsolidation of longterm memory in Aplysia. Curr. Biol. 22, 1783-1788. doi: 10.1016/j.cub.2012. 07.038

Cartron, L., Darmaillacq, A. S., and Dickel, L. (2013). The "prawn-in-the-tube" procedure: what do cuttlefish learn and memorize? Behav. Brain Res. 240, 2932. doi: 10.1016/j.bbr.2012.11.010

Cdc, C.F.D.C.a.P. (2005). "National Health and Nutrition Examination Survey," N.C.F.H.S. (NCHS) (Hyattsville, MD: U.S. Department of Health and Human Services, Centers for Disease Control and Prevention).

Cdc, C.F.D.C.a.P. (2007-2010). "National Health and Nutrition Examination Survey," N.C.F.H.S. (NCHS) (Hyattsville, MD: U.S. Department of Health and Human Services, Centers for Disease Control and Prevention).
Chen, C. H., Chen, Y. C., Jiang, H. C., Chen, C. K., and Pan, C. L. (2013). Neuronal aging: learning from C. elegans. J. Mol. Signal. 8:14. doi: 10.1186/1750-21878-14

Chen, W. F., Maguire, S., Sowcik, M., Luo, W., Koh, K., and Sehgal, A. (2014). A neuron-glia interaction involving GABA transaminase contributes to sleep loss in sleepless mutants. Mol. Psychiatry doi: 10.1038/mp.2014.11. [Epub ahead of print].

Cho, K., Ennaceur, A., Cole, J. C., and Suh, C. K. (2000). Chronic jet lag produces cognitive deficits. J. Neurosci. 20:RC66.

Cho, J. Y., and Sternberg, P. W. (2014). Multilevel modulation of a sensory motor circuit during C. elegans sleep and arousal. Cell 156, 249-260. doi: 10.1016/j.cell. 2013.11.036

Cirelli, C., and Tononi, G. (2008). Is sleep essential? PLoS Biol. 6:e216. doi: 10. 1371/journal.pbio.0060216

Collado Mateo, M. J., Díaz-Morales, J. F., Escribano Barreno, C., Delgado Prieto, P., and Randler, C. (2012). Morningness-eveningness and sleep habits among adolescents: age and gender differences. Psicothema 24, 410-415.

Corl, A. B., Berger, K. H., Ophir-Shohat, G., Gesch, J., Simms, J. A., Bartlett, S. E., et al. (2009). Happyhour, a Ste20 family kinase, implicates EGFR signaling in ethanol-induced behaviors. Cell 137, 949-960. doi: 10.1016/j.cell.2009. 03.020

Crook, R. J., Hanlon, R. T., and Walters, E. T. (2013). Squid have nociceptors that display widespread long-term sensitization and spontaneous activity after bodily injury. J. Neurosci. 33, 10021-10026. doi: 10.1523/ineurosci.0646-13.2013

Davis, R. L. (2011). Traces of Drosophila memory. Neuron 70, 8-19. doi: 10.1016/j. neuron.2011.03.012

Decker, S., Mcconnaughey, S., and Page, T. L. (2007). Circadian regulation of insect olfactory learning. Proc. Natl. Acad. Sci. U S A 104, 15905-15910. doi: 10. 1073/pnas.0702082104

Dibner, C., Schibler, U., and Albrecht, U. (2010). The mammalian circadian timing system: organization and coordination of central and peripheral clocks. Annu. Rev. Physiol. 72, 517-549. doi: 10.1146/annurev-physiol-021909135821

Dijk, D. J., Duffy, J. F., and Czeisler, C. A. (1992). Circadian and sleep/wake dependent aspects of subjective alertness and cognitive performance. J. Sleep Res. 1, 112-117. doi: 10.1111/j.1365-2869.1992.tb00021.x

Donlea, J. M., Pimentel, D., and Miesenböck, G. (2014). Neuronal machinery of sleep homeostasis in Drosophila. Neuron 81, 860-872. doi: 10.1016/j.neuron. 2014.03.008

Donlea, J. M., Ramanan, N., and Shaw, P. J. (2009). Use-dependent plasticity in clock neurons regulates sleep need in Drosophila. Science 324, 105-108. doi: 10. 1126/science.1166657

Donlea, J. M., Thimgan, M. S., Suzuki, Y., Gottschalk, L., and Shaw, P. J. (2011). Inducing sleep by remote control facilitates memory consolidation in Drosophila. Science 332, 1571-1576. doi: 10.1126/science.1202249

Driver, R. J., Lamb, A. L., Wyner, A. J., and Raizen, D. M. (2013). DAF-16/FOXO regulates homeostasis of essential sleep-like behavior during larval transitions in C. elegans. Curr. Biol. 23, 501-506. doi: 10.1016/j.cub.2013.02.009

Duntley, S. P., Uhles, M., and Feren, S. (2002). Sleep in the cuttlefish Sepia pharaonis. Sleep 25, A159-A160.

Eban-Rothschild, A., and Bloch, G. (2012). Social influences on circadian rhythms and sleep in insects. Adv. Genet. 77, 1-32. doi: 10.1016/b978-0-12-387687-4. 00001-5

Eban-Rothschild, A. D., and Bloch, G. (2008). Differences in the sleep architecture of forager and young honeybees (Apis mellifera). J. Exp. Biol. 211, 2408-2416. doi: $10.1242 /$ jeb. 016915

Evans, J. A., and Davidson, A. J. (2013). Health consequences of circadian disruption in humans and animal models. Prog. Mol. Biol. Transl. Sci. 119, 283-323. doi: 10.1016/b978-0-12-396971-2.00010-5

Fernandez, R. I., Lyons, L. C., Levenson, J., Khabour, O., and Eskin, A. (2003). Circadian modulation of long-term sensitization in Aplysia. Proc. Natl. Acad. Sci. U S A 100, 14415-14420. doi: 10.1073/pnas.2336172100

Fiorito, G., Affuso, A., Anderson, D. B., Basil, J., Bonnaud, L., Botta, G., et al. (2014). Cephalopods in neuroscience: regulations, research and the 3Rs. Invert. Neurosci. 14, 13-36. doi: 10.1007/s10158-013-0165-x

Fogle, K. J., Parson, K. G., Dahm, N. A., and Holmes, T. C. (2011). CRYPTOCHROME is a blue-light sensor that regulates neuronal firing rate. Science 331, 1409-1413. doi: 10.1126/science.1199702 
Frank, M. G., Waldrop, R. H., Dumoulin, M., Aton, S., and Boal, J. G. (2012). A preliminary analysis of sleep-like states in the cuttlefish Sepia officinalis. PLoS One 7:e38125. doi: 10.1371/journal.pone.0038125

Freeman, A. A., Syed, S., and Sanyal, S. (2013). Modeling the genetic basis for human sleep disorders in Drosophila. Commun. Integr. Biol. 6:e22733. doi: 10. 4161/cib. 22733

Fropf, R., Zhang, J., Tanenhaus, A. K., Fropf, W. J., Siefkes, E., and Yin, J. C. (2014). Time of day influences memory formation and dCREB2 proteins in Drosophila. Front. Syst. Neurosci. 8:43. doi: 10.3389/fnsys.2014.00043

Gage, S. L., Daly, K. C., and Nighorn, A. (2013). Nitric oxide affects short-term olfactory memory in the antennal lobe of Manduca sexta. J. Exp. Biol. 216, 3294 3300. doi: 10.1242/jeb.086694

Gage, S. L., and Nighorn, A. (2014). The role of nitric oxide in memory is modulated by diurnal time. Front. Syst. Neurosci. 8:59. doi: 10.3389/fnsys.2014. 00059

Ganguly-Fitzgerald, I., Donlea, J., and Shaw, P. J. (2006). Waking experience affects sleep need in Drosophila. Science 313, 1775-1781. doi: 10.1126/science.11 30408

Garren, M. V., Sexauer, S. B., and Page, T. L. (2013). Effect of circadian phase on memory acquisition and recall: operant conditioning vs. classical conditioning. PLoS One 8:e58693. doi: 10.1371/journal.pone.0058693

Gerstner, J. R., and Yin, J. C. (2010). Circadian rhythms and memory formation. Nat. Rev. Neurosci. 11, 577-588. doi: 10.1038/nrn2881

Gibson, E. M., Wang, C., Tjho, S., Khattar, N., and Kriegsfeld, L. J. (2010). Experimental 'jet lag' inhibits adult neurogenesis and produces long-term cognitive deficits in female hamsters. PLoS One 5:e15267. doi: 10.1371/journal.pone. 0015267

Gilestro, G. F., Tononi, G., and Cirelli, C. (2009). Widespread changes in synaptic markers as a function of sleep and wakefulness in Drosophila. Science 324, 109112. doi: 10.1126/science. 1166673

Goel, N., Basner, M., Rao, H., and Dinges, D. F. (2013). Circadian rhythms, sleep deprivation and human performance. Prog. Mol. Biol. Transl. Sci. 119, 155-190. doi: 10.1016/b978-0-12-396971-2.00007-5

Goel, N., Rao, H., Durmer, J. S., and Dinges, D. F. (2009). Neurocognitive consequences of sleep deprivation. Semin. Neurol. 29, 320-339. doi: 10.1055/s-00291237117

González, J., Gamundi, A., Rial, R., Nicolau, M. C., De Vera, L., and Pereda, E. (1999). Nonlinear, fractal and spectral analysis of the EEG of lizard, Gallotia galloti. Am. J. Physiol. 277, R86-R93.

Granados-Fuentes, D., Prolo, L. M., Abraham, U., and Herzog, E. D. (2004a). The suprachiasmatic nucleus entrains, but does not sustain, circadian rhythmicity in the olfactory bulb. J. Neurosci. 24, 615-619. doi: 10.1523/jneurosci.4002-03. 2004

Granados-Fuentes, D., Saxena, M. T., Prolo, L. M., Aton, S. J., and Herzog, E. D. (2004b). Olfactory bulb neurons express functional, entrainable circadian rhythms. Eur. J. Neurosci. 19, 898-906. doi: 10.1111/j.0953-816x.2004.03117.x

Granados-Fuentes, D., Tseng, A., and Herzog, E. D. (2006). A circadian clock in the olfactory bulb controls olfactory responsivity. J. Neurosci. 26, 12219-12225. doi: 10.1523/jneurosci.3445-06.2006

Grandner, M. A., Jackson, N. J., Pak, V. M., and Gehrman, P. R. (2012). Sleep disturbance is associated with cardiovascular and metabolic disorders. J. Sleep Res. 21, 427-433. doi: 10.1111/j.1365-2869.2011.00990.x

Gritton, H. J., Kantorowski, A., Sarter, M., and Lee, T. M. (2012). Bidirectional interactions between circadian entrainment and cognitive performance. Learn. Mem. 19, 126-141. doi: 10.1101/lm.023499.111

Hanlon, R. T., Naud, M. J., Forsythe, J. W., Hall, K., Watson, A. C., and Mckechnie, J. (2007). Adaptable night camouflage by cuttlefish. Am. Nat. 169, 543-551. doi: $10.1086 / 512106$

Haraszti, R. A., Ella, K., Gyöngyösi, N., Roenneberg, T., and Káldi, K. (2014). Social jetlag negatively correlates with academic performance in undergraduates. Chronobiol. Int. 31, 603-612. doi: 10.3109/07420528.2013.879164

Hardin, P. E. (2011). Molecular genetic analysis of circadian timekeeping in Drosophila. Adv. Genet. 74, 141-173. doi: 10.1016/b978-0-12-387690-4. 00005-2

Harris, J. J., Jolivet, R., and Attwell, D. (2012). Synaptic energy use and supply. Neuron 75, 762-777. doi: 10.1016/j.neuron.2012.08.019

Harris, C. A., Passaro, P. A., Kemenes, I., Kemenes, G., and O'shea, M. (2010). Sensory driven multi-neuronal activity and associative learning monitored in an intact CNS on a multielectrode array. J. Neurosci. Methods 186, 171-178. doi: 10. 1016/j.jneumeth.2009.11.014

Hawkins, R. D., Kandel, E. R., and Bailey, C. H. (2006). Molecular mechanisms of memory storage in Aplysia. Biol. Bull. 210, 174-191. doi: 10.2307/4134556

Hendricks, J. C., Finn, S. M., Panckeri, K. A., Chavkin, J., Williams, J. A., Sehgal, A., et al. (2000). Rest in Drosophila is a sleep-like state. Neuron 25, 129-138. doi: 10. 1016/s0896-6273(00)80877-6

Hobson, J. A., Goin, O. B., and Goin, C. J. (1968). Electrographic correlates of behaviour in tree frogs. Nature 220, 386-387. doi: 10.1038/220386a0

Hochner, B. (2010). Functional and comparative assessments of the octopus learning and memory system. Front. Biosci. (Schol. Ed.) 2, 764-771. doi: 10. $2741 /$ s 99

Hochner, B., Brown, E. R., Langella, M., Shomrat, T., and Fiorito, G. (2003). A learning and memory area in the octopus brain manifests a vertebrate-like long-term potentiation. J. Neurophysiol. 90, 3547-3554. doi: 10.1152/jn.00645. 2003

Holmes, M. C., French, K. L., and Seckl, J. R. (1995). Modulation of serotonin and corticosteroid receptor gene expression in the rat hippocampus with circadian rhythm and stress. Brain Res. Mol. Brain Res. 28, 186-192. doi: 10.1016/0169328x(94)00207-u

Horne, J. A., and Reyner, L. A. (1995). Sleep related vehicle accidents. BMJ 310, 565-567. doi: 10.1136/bmj.310.6979.565

Hsieh, S. D., Muto, T., Murase, T., Tsuji, H., and Arase, Y. (2011). Association of short sleep duration with obesity, diabetes, fatty liver and behavioral factors in Japanese men. Intern. Med. 50, 2499-2502. doi: 10.2169/internalmedicine.50. 5844

Hussaini, S. A., Bogusch, L., Landgraf, T., and Menzel, R. (2009). Sleep deprivation affects extinction but not acquisition memory in honeybees. Learn. Mem. 16, 698-705. doi: 10.1101/lm.1578409

Iwanir, S., Tramm, N., Nagy, S., Wright, C., Ish, D., and Biron, D. (2013). The microarchitecture of $C$. elegans behavior during lethargus: homeostatic bout dynamics, a typical body posture and regulation by a central neuron. Sleep 36, 385-395. doi: 10.5665/sleep. 2456

Jackson, F. R. (2011). Glial cell modulation of circadian rhythms. Glia 59, 1341 1350. doi: 10.1002/glia.21097

Jeon, M., Gardner, H. F., Miller, E. A., Deshler, J., and Rougvie, A. E. (1999). Similarity of the C. elegans developmental timing protein LIN-42 to circadian rhythm proteins. Science 286, 1141-1146. doi: 10.1126/science.286.5442. 1141

Jezzini, S. H., Bodnarova, M., and Moroz, L. L. (2005). Two-color in situ hybridization in the CNS of Aplysia californica. J. Neurosci. Methods 149, 15-25. doi: 10. 1016/j.jneumeth.2005.05.007

Jilg, A., Lesny, S., Peruzki, N., Schwegler, H., Selbach, O., Dehghani, F., et al. (2010). Temporal dynamics of mouse hippocampal clock gene expression support memory processing. Hippocampus 20, 377-388. doi: 10.1002/hipo.20637

Kaiser, W. (1988). Busy bees need rest, too. J. Comp. Physiol. A 163, 565-584. doi: $10.1007 / \mathrm{bf} 00603841$

Kaiser, W., and Steiner-Kaiser, J. (1983). Neuronal correlates of sleep, wakefulness and arousal in a diurnal insect. Nature 301, 707-709. doi: 10.1038/301707a0

Kandel, E. R. (2001). The molecular biology of memory storage: a dialogue between genes and synapses. Science 294, 1030-1038. doi: 10.1126/science.10 67020

Kandel, E. R., Dudai, Y., and Mayford, M. R. (2014). The molecular and systems biology of memory. Cell 157, 163-186. doi: 10.1016/j.cell.2014.03.001

Kapfhamer, D., Taylor, S., Zou, M. E., Lim, J. P., Kharazia, V., and Heberlein, U. (2013). Taok2 controls behavioral response to ethanol in mice. Genes Brain Behav. 12, 87-97. doi: 10.1111/j.1601-183x.2012.00834.x

Karatsoreos, I. N., Bhagat, S., Bloss, E. B., Morrison, J. H., and Mcewen, B. S. (2011). Disruption of circadian clocks has ramifications for metabolism, brain and behavior. Proc. Natl. Acad. Sci. U S A 108, 1657-1662. doi: 10.1073/pnas. 1018375108

Kaun, K. R., Devineni, A. V., and Heberlein, U. (2012). Drosophila melanogaster as a model to study drug addiction. Hum. Genet. 131, 959-975. doi: 10.1007/s00439012-1146-6

Kemenes, G., Kemenes, I., Michel, M., Papp, A., and Muller, U. (2006). Phasedependent molecular requirements for memory reconsolidation: differential roles for protein synthesis and protein kinase a activity. J. Neurosci. 26, 62986302. doi: 10.1523/jneurosci.0890-06.2006 
Klein, B. A., Olzsowy, K. M., Klein, A., Saunders, K. M., and Seeley, T. D. (2008). Caste-dependent sleep of worker honey bees. J. Exp. Biol. 211, 3028-3040. doi: 10.1242/jeb.017426

Knutson, K. L., Van Cauter, E., Rathouz, P. J., Deleire, T., and Lauderdale, D. S. (2010). Trends in the prevalence of short sleepers in the USA: 1975-2006. Sleep 33, 37-45.

Koh, K., Joiner, W. J., Wu, M. N., Yue, Z., Smith, C. J., and Sehgal, A. (2008). Identification of SLEEPLESS, a sleep-promoting factor. Science 321, 372-376. doi: 10.1126/science.1155942

Lagasse, F., Moreno, C., Preat, T., and Mery, F. (2012). Functional and evolutionary trade-offs co-occur between two consolidated memory phases in Drosophila melanogaster. Proc. Biol. Sci. 279, 4015-4023. doi: 10.1098/rspb.2012.1457

Landrigan, C. P., Rothschild, J. M., Cronin, J. W., Kaushal, R., Burdick, E., and Katz, J. T. (2004). Effect of reducing interns' work hours on serious medical errors in intensive care units. N. Engl. J. Med. 351, 1838-1848. doi: 10 1056/nejmoa041406

Le Glou, E., Seugnet, L., Shaw, P. J., Preat, T., and Goguel, V. (2012). Circadian modulation of consolidated memory retrieval following sleep deprivation in Drosophila. Sleep 35, 1377-1384B. doi: 10.5665/sleep.2118

Lehmann, M., Gustav, D., and Galizia, C. G. (2011). The early bee catches the flower - circadian rhythmicity influences learning performance in honey bees, Apis mellifera. Behav. Ecol. Sociobiol. 65, 205-215. doi: 10.1007/s00265-010-1026-9

Leproult, R., and Van Cauter, E. (2010). Role of sleep and sleep loss in hormonal release and metabolism. Endocr. Dev. 17, 11-21. doi: 10.1159/000262524

Li, J. Z., Bunney, B. G., Meng, F., Hagenauer, M. H., Walsh, D. M., Vawter, M. P., et al. (2013). Circadian patterns of gene expression in the human brain and disruption in major depressive disorder. Proc. Natl. Acad. Sci. U S A 110, 99509955. doi: 10.1073/pnas.1305814110

Li, X., Yu, F., and Guo, A. (2009). Sleep deprivation specifically impairs short-term olfactory memory in Drosophila. Sleep 32, 1417-1424.

Liu, S., Lamaze, A., Liu, Q., Tabuchi, M., Yang, Y., Fowler, M., et al. (2014). WIDE AWAKE mediates the circadian timing of sleep onset. Neuron 82, 151-166. doi: 10.1016/j.neuron.2014.01.040

Liu, R. Y., Zhang, Y., Baxter, D. A., Smolen, P., Cleary, L. J., and Byrne, J. H. (2013). Deficit in long-term synaptic plasticity is rescued by a computationally predicted stimulus protocol. J. Neurosci. 33, 6944-6949. doi: 10.1523/JNEUROSCI. 0643-13

Lo, J. C., Groeger, J. A., Santhi, N., Arbon, E. L., Lazar, A. S., Hasan, S., et al. (2012). Effects of partial and acute total sleep deprivation on performance across cognitive domains, individuals and circadian phase. PLoS One 7:e45987. doi: 10. 1371/journal.pone.0045987

Loh, D. H., Navarro, J., Hagopian, A., Wang, L. M., Deboer, T., and Colwell, C. S. (2010). Rapid changes in the light/dark cycle disrupt memory of conditioned fear in mice. PLoS One 5:e12546. doi: 10.1371/journal.pone.0012546

Luckhaupt, S. E. (2012). Short sleep duration among workers - United States, 2010. MMWR Morb. Mortal. Wkly. Rep. 61, 281-285.

Lukowiak, K., Sunada, H., Teskey, M., and Dalesman, S. (2014). Environmentally relevant stressors alter memory formation in the pond snail Lymnaea. J. Exp. Biol. 217, 76-83. doi: 10.1242/jeb.089441

Lyons, L. C. (2011). Critical role of the circadian clock in memory formation: lessons from Aplysia. Front. Mol. Neurosci. 4:52. doi: 10.3389/fnmol.2011.00052

Lyons, L. C., and Roman, G. (2008). Circadian modulation of short-term memory in Drosophila. Learn. Mem. 16, 19-27. doi: 10.1101/lm.1146009

Lyons, L. C., Collado, M. S., Khabour, O., Green, C. L., and Eskin, A. (2006a). The circadian clock modulates core steps in long-term memory formation in Aplysia. J. Neurosci. 26, 8662-8671. doi: 10.1523/jneurosci.2307-06.2006

Lyons, L. C., Green, C. L., and Eskin, A. (2008). Intermediate-term memory is modulated by the circadian clock. J. Biol. Rhythms 23, 538-542. doi: 10 $1177 / 0748730408325359$

Lyons, L. C., Rawashdeh, O., and Eskin, A. (2006b). Non-ocular circadian oscillators and photoreceptors modulate long term memory formation in Aplysia. J. Biol. Rhythms 21, 245-255. doi: 10.1177/0748730406289890

Lyons, L. C., Rawashdeh, O., Katzoff, A., Susswein, A. J., and Eskin, A. (2005). Circadian modulation of complex learning in diurnal and nocturnal Aplysia. Proc. Natl. Acad. Sci. U S A 102, 12589-12594. doi: 10.1073/pnas.0503847102

Lyznicki, J. M., Doege, T. C., Davis, R. M., and Williams, M. A. (1998). Sleepiness, driving and motor vehicle crashes. Council on scientific affairs, American medical association. JAMA 279, 1908-1913. doi: 10.1001/jama.279.23.1908
Madan, V., and Jha, S. K. (2012). Sleep alterations in mammals: did aquatic conditions inhibit rapid eye movement sleep? Neurosci. Bull. 28, 746-758. doi: 10.1007/s12264-012-1285-8

Marra, V., O'shea, M., Benjamin, P. R., and Kemenes, I. (2013). Susceptibility of memory consolidation during lapses in recall. Nat. Commun. 4:1578. doi: 10. 1038/ncomms 2591

Matthews, R. W., Ferguson, S. A., Zhou, X., Kosmadopoulos, A., Kennaway, D. J., and Roach, G. D. (2012a). Simulated driving under the influence of extended wake, time of day and sleep restriction. Accid. Anal. Prev. 45(Suppl.), 55-61. doi: 10.1016/j.aap.2011.09.027

Matthews, R. W., Ferguson, S. A., Zhou, X., Sargent, C., Darwent, D., Kennaway, D. J., et al. (2012b). Time-of-day mediates the influences of extended wake and sleep restriction on simulated driving. Chronobiol. Int. 29, 572-579. doi: 10. 3109/07420528.2012.675845

McGuire, S. E., Deshazer, M., and Davis, R. L. (2005). Thirty years of olfactory learning and memory research in Drosophila melanogaster. Prog. Neurobiol. 76, 328-347. doi: 10.1016/j.pneurobio.2005.09.003

Meisel, D. V., Byrne, R. A., Kuba, M., Mather, J., Ploberger, W., and Reschenhofer, E. (2006). Contrasting activity patterns of two related octopus species, Octopus macropus and Octopus vulgaris. J. Comp. Psychol. 120, 191-197. doi: 10. 1037/0735-7036.120.3.191

Mendoza-Angeles, K., Hernández-Falcón, J., and Ramón, F. (2010). Slow waves during sleep in crayfish. Origin and spread. J. Exp. Biol. 213, 2154-2164. doi: 10. 1242/jeb.038240

Mery, F., and Kawecki, T. J. (2005). A cost of long-term memory in Drosophila. Science 308:1148. doi: 10.1126/science.1111331

Michel, M., Gardner, J. S., Green, C. L., Organ, C. L., and Lyons, L. C. (2013). Protein phosphatase-dependent circadian regulation of intermediate-term associative memory. J. Neurosci. 33, 4605-4613. doi: 10.1523/jneurosci.4534-12.2013

Mohawk, J. A., Green, C. B., and Takahashi, J. S. (2012). Central and peripheral circadian clocks in mammals. Annu. Rev. Neurosci. 35, 445-462. doi: 10 1146/annurev-neuro-060909-153128

Moore, D., and Doherty, P. (2009). Acquisition of a time-memory in forager honey bees. J. Comp. Physiol. A Neuroethol. Sens. Neural Behav. Physiol. 195, 741-751. doi: 10.1007/s00359-009-0450-7

Moore, D., Van Nest, B. N., and Seier, E. (2011). Diminishing returns: the influence of experience and environment on time-memory extinction in honey bee foragers. J. Comp. Physiol. A Neuroethol. Sens. Neural Behav. Physiol. 197, 641651. doi: 10.1007/s00359-011-0624-y

Moroz, L. L. (2000). Giant identified NO-releasing neurons and comparative histochemistry of putative nitrergic systems in gastropod molluscs. Microsc. Res. Tech. 49, 557-569. doi: 10.1002/1097-0029(20000615)49:6<557::aid-jemt6>3. 3.co; $2-\mathrm{j}$

Moroz, L. L., and Kohn, A. B. (2013). Single-neuron transcriptome and methylome sequencing for epigenomic analysis of aging. Methods Mol. Biol. 1048, 323-352. doi: 10.1007/978-1-62703-556-9_21

Mozzachiodi, R., and Byrne, J. H. (2010). More than synaptic plasticity: role of nonsynaptic plasticity in learning and memory. Trends Neurosci. 33, 17-26. doi: 10.1016/j.tins.2009.10.001

Mukhametov, L. M. (1987). Unihemispheric slow-wave sleep in the amazonian dolphin, inia geoffrensis. Neurosci. Lett. 79, 128-132. doi: 10.1016/03043940(87)90684-7

Mukhametov, L. M., Supin, A. Y., and Polyakova, I. G. (1977). Interhemispheric asymmetry of the electroencephalographic sleep patterns in dolphins. Brain Res. 134, 581-584. doi: 10.1016/0006-8993(77)90835-6

Murakami, S. (2007). Caenorhabditis elegans as a model system to study aging of learning and memory. Mol. Neurobiol. 35, 85-94. doi: 10.1007/bf02700625

Neckelmann, D., Mykletun, A., and Dahl, A. A. (2007). Chronic insomnia as a risk factor for developing anxiety and depression. Sleep 30, 873-880.

Nelson, M. D., and Raizen, D. M. (2013). A sleep state during C. elegans development. Curr. Opin. Neurobiol. 23, 824-830. doi: 10.1016/j.conb.2013.02.015

Nemes, P., Rubakhin, S. S., Aerts, J. T., and Sweedler, J. V. (2013). Qualitative and quantitative metabolomic investigation of single neurons by capillary electrophoresis electrospray ionization mass spectrometry. Nat. Protoc. 8, 783 799. doi: 10.1038/nprot.2013.035

Nicol, S. C., Andersen, N. A., Phillips, N. H., and Berger, R. J. (2000). The echidna manifests typical characteristics of rapid eye movement sleep. Neurosci. Lett. 283, 49-52. doi: 10.1016/s0304-3940(00)00922-8 
Nikitin, E. S., Balaban, P. M., and Kemenes, G. (2013). Nonsynaptic plasticity underlies a compartmentalized increase in synaptic efficacy after classical conditioning. Curr. Biol. 23, 614-619. doi: 10.1016/j.cub.2013.02.048

Orozco-Solis, R., and Sassone-Corsi, P. (2014). Epigenetic control and the circadian clock: linking metabolism to neuronal responses. Neuroscience 264C, 76-87. doi: 10.1016/j.neuroscience.2014.01.043

Ozkaya, O., and Rosato, E. (2012). The circadian clock of the fly: a neurogenetics journey through time. Adv. Genet. 77, 79-123. doi: 10.1016/b978-0-12-3876874.00004-0

Pack, A. I., Pack, A. M., Rodgman, E., Cucchiara, A., Dinges, D. F., and Schwab, C. W. (1995). Characteristics of crashes attributed to the driver having fallen asleep. Accid. Anal. Prev. 27, 769-775. doi: 10.1016/0001-4575(95) 00034-8

Park, S., Sonn, J. Y., Oh, Y., Lim, C., and Choe, J. (2014). SIFamide and SIFamide receptor defines a novel neuropeptide signaling to promote sleep in Drosophila. Mol. Cells 37, 295-301. doi: 10.14348/molcells.2014.2371

Pereyra, P., De La Iglesia, H. O., and Maldonado, H. (1996). Training-to-testing intervals different from $24 \mathrm{~h}$ impair habituation in the crab Chasmagnathus. Physiol. Behav. 59, 19-25. doi: 10.1016/0031-9384(95)02013-6

Peterson, K. J., Lyons, J. B., Nowak, K. S., Takacs, C. M., Wargo, M. J., and Mcpeek, M. A. (2004). Estimating metazoan divergence times with a molecular clock. Proc. Natl. Acad. Sci. U S A 101, 6536-6541. doi: 10.1073/pnas.0401670101

Philips, G. T., Sherff, C. M., Menges, S. A., and Carew, T. J. (2011). The tailelicited tail withdrawal reflex of Aplysia is mediated centrally at tail sensorymotor synapses and exhibits sensitization across multiple temporal domains. Learn. Mem. 18, 272-282. doi: 10.1101/lm.2125311

Philips, G. T., Tzvetkova, E. I., Marinesco, S., and Carew, T. J. (2006). Latent memory for sensitization in Aplysia. Learn. Mem. 13, 224-229. doi: 10.1101/lm. 111506

Piscopo, S. (2009). Sleep and its possible role in learning: a phylogenetic view. Front. Biosci. (Schol. Ed.) 1, 437-447. doi: 10.2741/e36

Plaçais, P. Y., and Preat, T. (2013). To favor survival under food shortage, the brain disables costly memory. Science 339, 440-442. doi: 10.1126/science.1226018

Plautz, J. D., Kaneko, M., Hall, J. C., and Kay, S. A. (1997). Independent photoreceptive circadian clocks throughout Drosophila. Science 278, 1632-1635. doi: 10. 1126/science.278.5343.1632

Pluquet, O., Dejeans, N., and Chevet, E. (2014). Watching the clock: endoplasmic reticulum-mediated control of circadian rhythms in cancer. Ann. Med. 46, 233243. doi: 10.3109/07853890.2013.874664

Potdar, S., and Sheeba, V. (2013). Lessons from sleeping flies: insights from Drosophila melanogaster on the neuronal circuitry and importance of sleep. J. Neurogenet. 27, 23-42. doi: 10.3109/01677063.2013.791692

Preston, R. J., and Lee, R. M. (1973). Feeding behavior in Aplysia californica: role of chemical and tactile stimuli. J. Comp. Physiol. Psychol. 82, 368-381. doi: 10. 1037/h0034132

Preuss, F., Tang, Y., Laposky, A. D., Arble, D., Keshavarzian, A., and Turek, F. W. (2008). Adverse effects of chronic circadian desynchronization in animals in a "challenging" environment. Am. J. Physiol. Regul. Integr. Comp. Physiol. 295, R2034-R2040. doi: 10.1152/ajpregu.00118.2008

Prolo, L. M., Takahashi, J. S., and Herzog, E. D. (2005). Circadian rhythm generation and entrainment in astrocytes. J. Neurosci. 25, 404-408. doi: 10. 1523/jneurosci.4133-04.2005

Puthanveettil, S. V., Antonov, I., Kalachikov, S., Rajasethupathy, P., Choi, Y. B., Kohn, A. B., et al. (2013). A strategy to capture and characterize the synaptic transcriptome. Proc. Natl. Acad. Sci. U S A 110, 7464-7469. doi: 10.1073/pnas. 1304422110

Ramón, F., Hernández-Falcón, J., Nguyen, B., and Bullock, T. H. (2004). Slow wave sleep in crayfish. Proc. Natl. Acad. Sci. U S A 101, 11857-11861. doi: 10. 1073/pnas.0402015101

Ramon, F., Mendoza-Angeles, K., and Hernandez-Falcon, J. (2012). Sleep in invertebrates: crayfish. Front. Biosci. (Schol. Ed.) 4, 1190-1200. doi: 10.2741/s325

Rattenborg, N. C. (2006). Evolution of slow-wave sleep and palliopallial connectivity in mammals and birds: a hypothesis. Brain Res. Bull. 69, 20-29. doi: 10. 1016/j.brainresbull.2005.11.002

Rattenborg, N. C. (2007). Response to commentary on evolution of slow-wave sleep and palliopallial connectivity in mammals and birds: a hypothesis. Brain Res. Bull. 72, 187-193. doi: 10.1016/j.brainresbull.2007.02.010
Rattenborg, N. C., Lima, S. L., and Lesku, J. A. (2012). Sleep locally, act globally. Neuroscientist 18, 533-546. doi: 10.1177/1073858412441086

Roenneberg, T. (2013). Chronobiology: the human sleep project. Nature 498, $427-$ 428. doi: $10.1038 / 498427$ a

Sakai, T., Tamura, T., Kitamoto, T., and Kidokoro, Y. (2004). A clock gene, period, plays a key role in long-term memory formation in Drosophila. Proc. Natl. Acad. Sci. US A 101, 16058-16063. doi: 10.1073/pnas.0401472101

Sasakura, H., and Mori, I. (2013). Behavioral plasticity, learning and memory in C. elegans. Curr. Opin. Neurobiol. 23, 92-99. doi: 10.1016/j.conb.2012.09.005

Sattelle, D. B., and Buckingham, S. D. (2006). Invertebrate studies and their ongoing contributions to neuroscience. Invert. Neurosci. 6, 1-3. doi: 10.1007/s10158-0050014-7

Sauer, S., Herrmann, E., and Kaiser, W. (2004). Sleep deprivation in honey bees. J. Sleep Res. 13, 145-152. doi: 10.1111/j.1365-2869.2004.00393.x

Sauer, S., Kinkelin, M., Herrmann, E., and Kaiser, W. (2003). The dynamics of sleep-like behaviour in honey bees. J. Comp. Physiol. A Neuroethol. Sens. Neural Behav. Physiol. 189, 599-607. doi: 10.1007/s00359-003-0436-9

Schaaf, M. J., Duurland, R., De Kloet, E. R., and Vreugdenhil, E. (2000). Circadian variation in BDNF mRNA expression in the rat hippocampus. Brain Res. Mol. Brain Res. 75, 342-344. doi: 10.1016/s0169-328x(99)00314-9

Schacher, S., and Hu, J. Y. (2014). The less things change, the more they are different: contributions of long-term synaptic plasticity and homeostasis to memory. Learn. Mem. 21, 128-134. doi: 10.1101/lm.027326.112

Schwarz, J., Lewandrowski, I., and Bringmann, H. (2011). Reduced activity of a sensory neuron during a sleep-like state in Caenorhabditis elegans. Curr. Biol. 21, R983-R984. doi: 10.1016/j.cub.2011.10.046

Sekiguchi, Y., and Kohshima, S. (2003). Resting behaviors of captive bottlenose dolphins (Tursiops truncatus). Physiol. Behav. 79, 643-653. doi: 10.1016/s00319384(03)00119-7

Seugnet, L., Galvin, J. E., Suzuki, Y., Gottschalk, L., and Shaw, P. J. (2009). Persistent short-term memory defects following sleep deprivation in a Drosophila model of Parkinson disease. Sleep 32, 984-992.

Seugnet, L., Suzuki, Y., Donlea, J. M., Gottschalk, L., and Shaw, P. J. (2011). Sleep deprivation during early-adult development results in long-lasting learning deficits in adult Drosophila. Sleep 34, 137-146.

Shaw, P. J., Cirelli, C., Greenspan, R. J., and Tononi, G. (2000). Correlates of sleep and waking in Drosophila melanogaster. Science 287, 1834-1837. doi: 10. 1126/science.287.5459.1834

Shi, M., Yue, Z., Kuryatov, A., Lindstrom, J. M., and Sehgal, A. (2014). Identification of Redeye, a new sleep-regulating protein whose expression is modulated by sleep amount. Elife 3:e01473. doi: 10.7554/elife.01473

Shomrat, T., Zarrella, I., Fiorito, G., and Hochner, B. (2008). The octopus vertical lobe modulates short-term learning rate and uses LTP to acquire long-term memory. Curr. Biol. 18, 337-342. doi: 10.1016/j.cub.2008.01.056

Siegel, J. M., Manger, P. R., Nienhuis, R., Fahringer, H. M., and Pettigrew, J. D. (1996). The echidna Tachyglossus aculeatus combines REM and non-REM aspects in a single sleep state: implications for the evolution of sleep. J. Neurosci. 16, 3500-3506.

Siegel, J. M., Manger, P. R., Nienhuis, R., Fahringer, H. M., and Pettigrew, J. D. (1998). Monotremes and the evolution of rapid eye movement sleep. Philos. Trans. R. Soc. Lond. B Biol. Sci. 353, 1147-1157. doi: 10.1098/rstb.1998.0272

Siegel, J. M., Manger, P. R., Nienhuis, R., Fahringer, H. M., Shalita, T., and Pettigrew, J. D. (1999). Sleep in the platypus. Neuroscience 91, 391-400. doi: 10.1016/s03064522(98)00588-0

Silva, E. J., Wang, W., Ronda, J. M., Wyatt, J. K., and Duffy, J. F. (2010). Circadian and wake-dependent influences on subjective sleepiness, cognitive throughput and reaction time performance in older and young adults. Sleep 33, 481-490.

Stein, G. M., and Murphy, C. T. (2012). The intersection of aging, longevity pathways and learning and memory in C. elegans. Front. Genet. 3:259. doi: 10. 3389/fgene.2012.00259

Stephenson, R. (2011). Sleep homeostasis: progress at a snail's pace. Commun. Integr. Biol. 4, 446-449. doi: 10.4161/cib.4.4.15540

Stephenson, R., and Lewis, V. (2011). Behavioural evidence for a sleep-like quiescent state in a pulmonate mollusc, Lymnaea stagnalis (Linnaeus). J. Exp. Biol. 214, 747-756. doi: 10.1242/jeb.050591

Strumwasser, F. (1971). The cellular basis of behavior in Aplysia. J. Psychiatr. Res. 8, 237-257. doi: 10.1016/b978-0-08-017007-7.50012-4 
Strumwasser, F. (1973). Seventeenth bowditch lecture. Neural and humoral factors in the temporal organization of behavior. Physiologist 16, 9-42.

Suka, M., Yoshida, K., and Sugimori, H. (2003). Persistent insomnia is a predictor of hypertension in Japanese male workers. J. Occup. Health 45, 344-350. doi: 10. 1539/joh.45.344

Sweedler, J. V., Li, L., Rubakhin, S. S., Alexeeva, V., Dembrow, N. C., Dowling, O., et al. (2002). Identification and characterization of the feeding circuitactivating peptides, a novel neuropeptide family of Aplysia. J. Neurosci. 22, 77977808.

Thimgan, M. S., Gottschalk, L., Toedebusch, C., Mcleland, J., Rechtschaffen, A., Gilliland-Roberts, M., et al. (2013). Cross-translational studies in human and Drosophila identify markers of sleep loss. PLoS One 8:e61016. doi: 10. 1371/journal.pone.0061016

Tobler, I. (1983). Effect of forced locomotion on the rest-activity cycle of the cockroach. Behav. Brain Res. 8, 351-360. doi: 10.1016/0166-4328(83)90180-8

Tobler, I., and Neuner-Jehle, M. (1992). 24-h variation of vigilance in the cockroach Blaberus giganteus. J. Sleep Res. 1, 231-239. doi: 10.1111/j.1365-2869.1992. tb00044.x

Tononi, G., and Cirelli, C. (2003). Sleep and synaptic homeostasis: a hypothesis. Brain Res. Bull. 62, 143-150. doi: 10.1016/j.brainresbull.2003.09.004

Tononi, G., and Cirelli, C. (2006). Sleep function and synaptic homeostasis. Sleep Med. Rev. 10, 49-62. doi: 10.1016/j.smrv.2005.05.002

Tononi, G., and Cirelli, C. (2012). Time to be SHY? Some comments on sleep and synaptic homeostasis. Neural Plast. 2012:415250. doi: 10.1155/2012/ 415250

Tononi, G., and Cirelli, C. (2014). Sleep and the price of plasticity: from synaptic and cellular homeostasis to memory consolidation and integration. Neuron 81 , 12-34. doi: 10.1016/j.neuron.2013.12.025

Touitou, Y. (2013). Adolescent sleep misalignment: a chronic jet lag and a matter of public health. J. Physiol. Paris 107, 323-326. doi: 10.1016/j.jphysparis.2013. 03.008

Turek, M., Lewandrowski, I., and Bringmann, H. (2013). An AP2 transcription factor is required for a sleep-active neuron to induce sleep-like quiescence in C. elegans. Curr. Biol. 23, 2215-2223. doi: 10.1016/j.cub.2013.09.028

van Alphen, B., Yap, M. H., Kirszenblat, L., Kottler, B., and van Swinderen, B. (2013). A dynamic deep sleep stage in Drosophila. J. Neurosci. 33, 6917-6927. doi: 10.1523/jneurosci.0061-13.2013

Vavoulis, D. V., Straub, V. A., Kemenes, I., Kemenes, G., Feng, J., and Benjamin, P. R. (2007). Dynamic control of a central pattern generator circuit: a computational model of the snail feeding network. Eur. J. Neurosci. 25, 2805-2818. doi: 10. 1111/j.1460-9568.2007.05517.x

Vgontzas, A. N., Liao, D., Bixler, E. O., Chrousos, G. P., and Vela-Bueno, A. (2009). Insomnia with objective short sleep duration is associated with a high risk for hypertension. Sleep 32, 491-497.

Vorster, A., Krishnan, H. C., Cirelli, C., and Lyons, L. C. (in press). Characterization of sleep in Aplysia californica. Sleep.

Wagatsuma, A., Sugai, R., Chono, K., Azami, S., Hatakeyama, D., Sadamoto, H., et al. (2004). The early snail acquires the learning. Comparison of scores for conditioned taste aversion between morning and afternoon. Acta Biol. Hung. 55, 149-155. doi: 10.1556/abiol.55.2004.1-4.18

Walters, E. T., and Moroz, L. L. (2009). Molluscan memory of injury: evolutionary insights into chronic pain and neurological disorders. Brain Behav. Evol. 74, 206 218. doi: $10.1159 / 000258667$

Wells, M. J. (1965). The vertical lobe and touch learning in the octopus. J. Exp. Biol. 42, 233-255.

Wells, M. J., and Young, J. Z. (1965). Split-brain preparations and touch learning in the octopus. J. Exp. Biol. 43, 565-579.

Weragoda, R. M., and Walters, E. T. (2007). Serotonin induces memorylike, rapamycin-sensitive hyperexcitability in sensory axons of Aplysia that contributes to injury responses. J. Neurophysiol. 98, 1231-1239. doi: 10.1152/jn. 01189.2006

Whitmore, D., Foulkes, N. S., and Sassone-Corsi, P. (2000). Light acts directly on organs and cells in culture to set the vertebrate circadian clock. Nature 404, 8791. doi: 10.1038/35003589

Williams, H. L., Holloway, F. A., and Griffiths, W. J. (1973). Physiological psychology: sleep. Annu. Rev. Psychol. 24, 279-316. doi: 10.1146/annurev.ps.24.020173. 001431

Wittmann, M., Dinich, J., Merrow, M., and Roenneberg, T. (2006). Social jetlag: misalignment of biological and social time. Chronobiol. Int. 23, 497-509. doi: 10. 1080/07420520500545979

Wright, K. P., Hull, J. T., and Czeisler, C. A. (2002). Relationship between alertness, performance and body temperature in humans. Am. J. Physiol. Regul. Integr. Comp. Physiol. 283, R1370-R1377. doi: 10.1152/ajpregu.00205.2002

Wright, K. P., Hull, J. T., Hughes, R. J., Ronda, J. M., and Czeisler, C. A. (2006). Sleep and wakefulness out of phase with internal biological time impairs learning in humans. J. Cogn. Neurosci. 18, 508-521. doi: 10.1162/jocn.2006.18.4.508

Wright, K. P., Lowry, C. A., and Lebourgeois, M. K. (2012). Circadian and wakefulness-sleep modulation of cognition in humans. Front. Mol. Neurosci. 5:50. doi: 10.3389/fnmol.2012.00050

Wu, M., Robinson, J. E., and Joiner, W. J. (2014). SLEEPLESS is a bifunctional regulator of excitability and cholinergic synaptic transmission. Curr. Biol. 24, 621-629. doi: 10.1016/j.cub.2014.02.026

Ye, X., Marina, A., and Carew, T. J. (2012). Local synaptic integration of mitogenactivated protein kinase and protein kinase a signaling mediates intermediateterm synaptic facilitation in Aplysia. Proc. Natl. Acad. Sci. U S A 109, 18162 18167. doi: 10.1073/pnas.1209956109

Yoo, S. H., Yamazaki, S., Lowrey, P. L., Shimomura, K., Ko, C. H., Buhr, E. D., et al (2004). PERIOD2::LUCIFERASE real-time reporting of circadian dynamics reveals persistent circadian oscillations in mouse peripheral tissues. Proc. Natl. Acad. Sci. U S A 101, 5339-5346. doi: 10.1073/pnas.0308709101

You, Y. J., Kim, J., Raizen, D. M., and Avery, L. (2008). Insulin, cGMP and TGF-beta signals regulate food intake and quiescence in C. elegans: a model for satiety. Cell Metab. 7, 249-257. doi: 10.1016/j.cmet.2008.01.005

Zhang, Y., Liu, R. Y., Heberton, G. A., Smolen, P., Baxter, D. A., Cleary, L. J., et al (2011). Computational design of enhanced learning protocols. Nat. Neurosci. 15, 294-297. doi: 10.1038/nn.2990

Zimmerman, J. E., Naidoo, N., Raizen, D. M., and Pack, A. I. (2008). Conservation of sleep: insights from non-mammalian model systems. Trends Neurosci. 31, 371-376. doi: 10.1016/j.tins.2008.05.001

Zullo, L., and Hochner, B. (2011). A new perspective on the organization of an invertebrate brain. Commun. Integr. Biol. 4, 26-29. doi: 10.4161/cib.4.1.13804

Conflict of Interest Statement: The authors declare that the research was conducted in the absence of any commercial or financial relationships that could be construed as a potential conflict of interest.

Received: 03 April 2014; paper pending published: 05 June 2014; accepted: 07 July 2014; published online: 04 August 2014.

Citation: Michel M and Lyons LC (2014) Unraveling the complexities of circadian and sleep interactions with memory formation through invertebrate research. Front. Syst. Neurosci. 8:133. doi: 10.3389/fnsys.2014.00133

This article was submitted to the journal Frontiers in Systems Neuroscience.

Copyright (C) 2014 Michel and Lyons. This is an open-access article distributed under the terms of the Creative Commons Attribution License (CC BY). The use, distribution or reproduction in other forums is permitted, provided the original author (s) or licensor are credited and that the original publication in this journal is cited, in accordance with accepted academic practice. No use, distribution or reproduction is permitted which does not comply with these terms. 